\title{
Intraoperative device closure of perimembranous ventricular septal defects without cardiopulmonary bypass: Preliminary results with the perventricular technique
}

Zahid Amin, MD

David A. Danford, MD

John Lof, MS

Kim F. Duncan, MD

Stacey Froemming, BS
From the University of Nebraska/Creighton University, Joint Division of Pediatric Cardiology, Children's Hospital of Omaha, Omaha, Neb.

Read at the Eighty-third Annual Meeting of The American Association for Thoracic Surgery, Boston, Mass, May 4-7, 2003.

Received for publication May 2, 2003; revisions requested Aug 14, 2003; accepted for publication Aug 25, 2003.

Address for reprints: Zahid Amin, MD, Children's Hospital of Omaha, 8200 Dodge St, 4th Floor Health Care Pavilion, Omaha, NE 68114 (E-mail: zamin@chsomaha.org).

J Thorac Cardiovasc Surg 2004;127:234-41

$0022-5223 / \$ 30.00$

Copyright ( $\odot 2004$ by The American Association for Thoracic Surgery

doi:10.1016/j.jtcvs.2003.08.023
Objective: In infants undergoing closure of perimembranous ventricular septal defects, cardiopulmonary bypass remains one of the factors that prolongs hospital stay and morbidity. A new technique was used to close the defects under echocardiographic guidance without cardiopulmonary bypass to prevent the deleterious effects of bypass.

Methods: Recently, the Amplatzer membranous ventricular septal defect device (AGA Medical Corp, Golden Valley, Minn) was introduced. The device has a double-disc design with a short connecting waist. The left ventricular disc has an eccentric design to prevent encroachment on the aortic valve leaflets. Eight Yucatan miniature pigs with naturally occurring perimembranous ventricular septal defects underwent closure of the defect in the operating room by using the perventricular technique. After median sternotomy, a purse-string suture was placed on the free wall of the right ventricle. An angiocatheter was advanced in the right ventricle, and through the catheter, a wire was advanced from the right ventricle through the ventricular septal defect into the left ventricle. A delivery sheath and the dilator were advanced over the wire. The wire and catheter were removed, and an appropriately sized Amplatzer membranous device was advanced through the sheath. The device was deployed under echocardiographic guidance with the heart beating.

Results: The procedure was successful in all animals. There was no incidence of device embolization, heart block, or aortic insufficiency. Angiograms at 3 and 6 months revealed no residual defects and no aortic insufficiency. Pathologically, the devices were completely endothelialized when examined grossly.

Conclusions: The perventricular technique appears to be excellent for closure of perimembranous ventricular septal defects in the operating room. The technique might be feasible in smaller babies, who are high-risk candidates for closure in the catheterization laboratory. Cardiopulmonary bypass and prolonged hospital stay are avoided.

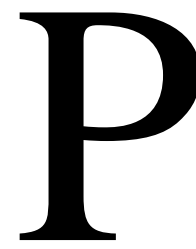
erimembranous (or conoventricular) ventricular septal defects (PMVSDs) are among the most common congenital cardiac malformations. ${ }^{1,2}$ Closure is routinely performed with the patient undergoing cardiopulmonary bypass (CPB), with excellent results. ${ }^{2-4} \mathrm{CPB}$ and sternotomy are important factors that might lead to increased postoperative morbidity, prolonged hospital stay, and possible late neurocognitive impairment. ${ }^{5}$ The long-term effects of CPB remain elusive, and its effects are more pronounced in infants than in patients of older age. ${ }^{6}$ We describe a new 


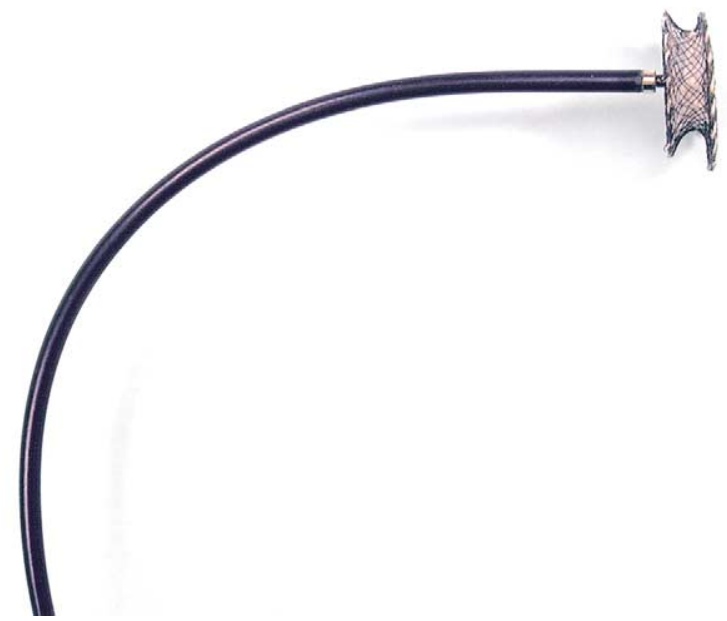

Figure 1. Amplatzer membranous VSD occluder attached to the delivery catheter.

technique to close PMVSDs in which the defects were closed under echocardiographic guidance without CPB.

\section{Methods}

All animals received humane care in compliance with the "Guide for the Care and Use of Laboratory Animals" prepared by the Institutes of Laboratory Animal Resources and published by the National Institute of Health (publication no. 86-23, revised 1985). The study was approved by the Institutional Animal Care and Use Committee of the University of Nebraska Medical Center, Omaha, Neb.

\section{Animal Model}

Yucatan miniature pigs with naturally occurring PMVSDs were used in this study. These pigs have naturally occurring PMVSDs that are similar to those of human beings. The defects are located under the anteroseptal commissure of the tricuspid valve and are subaortic in location when viewed from the left ventricular side.

\section{Amplatzer PMVSD Occluder}

The Amplatzer PMVSD Occluder device (AGA Medical Corp, Golden Valley, Minn) is made of 0.004-inch Nitinol wire mesh (Figure 1). The wires are shaped to form double discs, with a short connecting waist measuring $1.5 \mathrm{~mm}$. Dacron is sewn inside the discs to decrease shunting through the wire mesh. The device is self-expandable and fully retrievable to the point of release. The size of the device corresponds to the waist of the device. The edge of the left ventricular disc, which is to face the aortic valve, is only $0.5 \mathrm{~mm}$ larger than the waist to prevent impingement of the aortic valve. The edge of the disc opposite the aortic valve is $5 \mathrm{~mm}$ larger than the waist. The right ventricular disc is $2 \mathrm{~mm}$ larger than the waist all around its circumference. A female screw is welded in the center of the right disc for attachment to the delivery cable. The device is designed to be deployed percutaneously from the right ventricular side with a slightly complex delivery system to ensure

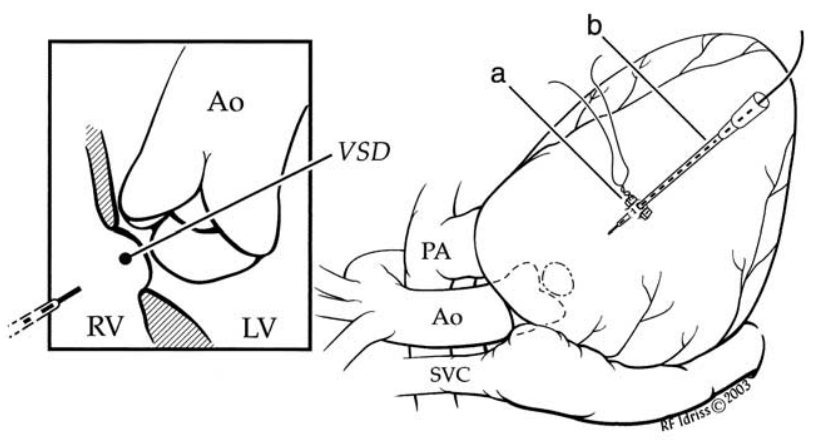

Figure 2. Angiocatheter (b) inserted through the purse-string suture (a) on the right ventricular free wall. A wire is advanced through the angiocatheter and aimed toward the VSD (inset). Ao, Aorta; $R V$, right ventricle; $L V$, left ventricle; $P A$, pulmonary artery; $S V C$, superior vena cava.

that the device orientation is maintained (the flat edge toward the aortic valve). For the perventricular approach, however, a simple delivery sheath is used because the device can be easily rotated at the time of deployment. The device is available in sizes ranging from 4 to $18 \mathrm{~mm}$, with 2 -mm increments. The delivery sheath size is dependent on the size of the device and ranges from $6 \mathrm{~F}$ to $9 \mathrm{~F}$.

\section{Perventricular Technique}

The pigs' weight ranged from 17 to $53 \mathrm{~kg}$, with 7 pigs weighing less than $25 \mathrm{~kg}$. All pigs except one were less than 3 months old at the time of the procedure.

The perventricular technique for closure of muscular ventricular septal defects (VSDs) has been described in previous studies. ${ }^{7,8}$ The procedure remains the same for PMVSDs. The chest was opened through a median sternotomy. The pericardium was cradled. A purse-string suture of 4-0 or 5-0 Prolene sutures (Ethicon, Somerville, NJ) was placed on the free wall of the right ventricle. Epicardial echocardiography was performed to measure the exact size and location of the PMVSD. The integrity of the aortic valve was evaluated. An angiocatheter was passed into the right ventricle through the free wall of the right ventricle, and the needle was removed (Figure 2). A 0.035-inch floppy or glide wire was advanced through the angiocatheter and aimed toward the PMVSD. The PMVSD was crossed, and the wire was advanced through the aortic valve in the ascending aorta (Figure 3). The dilator was removed, and an appropriately sized delivery sheath was advanced over the wire into the ascending aorta (Figure 4). The wire and the dilator were removed, and the sheath was allowed to back bleed to ensure there was no air entrapment. The Amplatzer PMVSD device was immersed in saline and screwed on to the delivery cable. The device was loaded with the help of a loader. The loader was introduced into the delivery sheath, and the device was advanced to the tip of the sheath (Figure 5). The sheath was gently pulled back until the tip was in the left ventricle, just under the aortic valve (Figure 6). Under echocardiographic guidance, the left disc was deployed; the sheath and the device were pulled back until the left disc approximated the ventricular septum (Figure 6). The device was gently rotated only if the flat part of the disc was not directly under the aortic valve. The waist and the right disc 


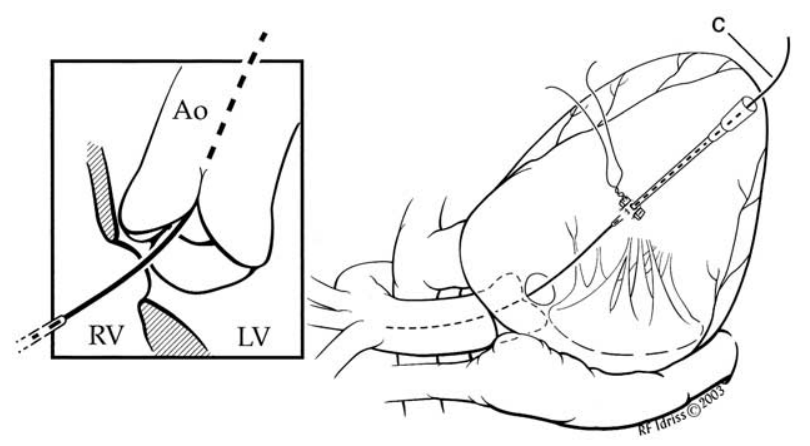

Figure 3. The wire (c) is advanced through the VSD and aortic valve to the ascending aorta. Ao, Aorta; $R V$, right ventricle; $L V$, left ventricle.

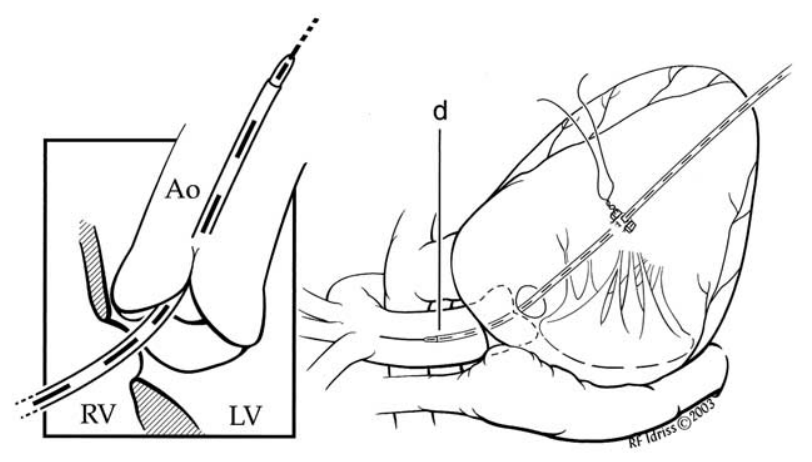

Figure 4. The delivery sheath (d) and the dilator are advanced over the wire into the aorta. Ao, Aorta; $R V$, right ventricle; $L V$, left ventricle.

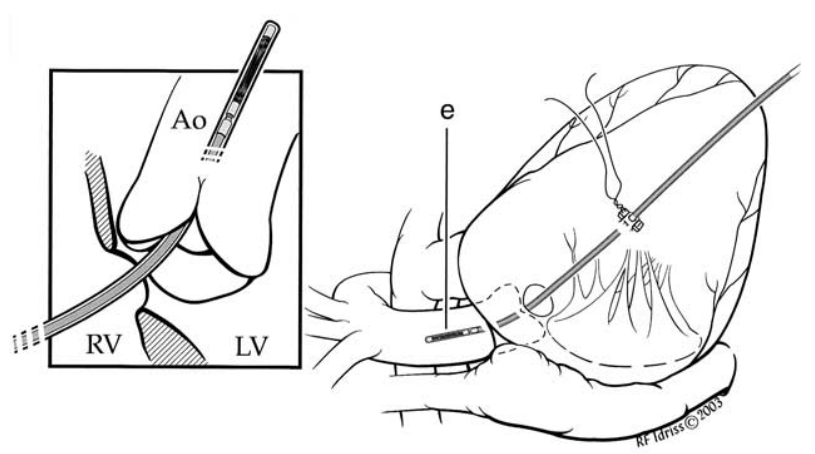

Figure 5. The Amplatzer membranous occluder (e) is advanced through the delivery sheath after removing the dilator. Ao, Aorta; $R V$, right ventricle; $L V$, left ventricle.

were deployed while maintaining fair traction on the delivery cable (Figure 7, A). The position of the device was checked, the aortic valve was evaluated for aortic insufficiency, and the device was released by rotating the delivery cable anticlockwise (Figure 7, B). The sheath and the delivery cable were pulled out of the right ventricle, and the purse-string suture on the right ventricle free

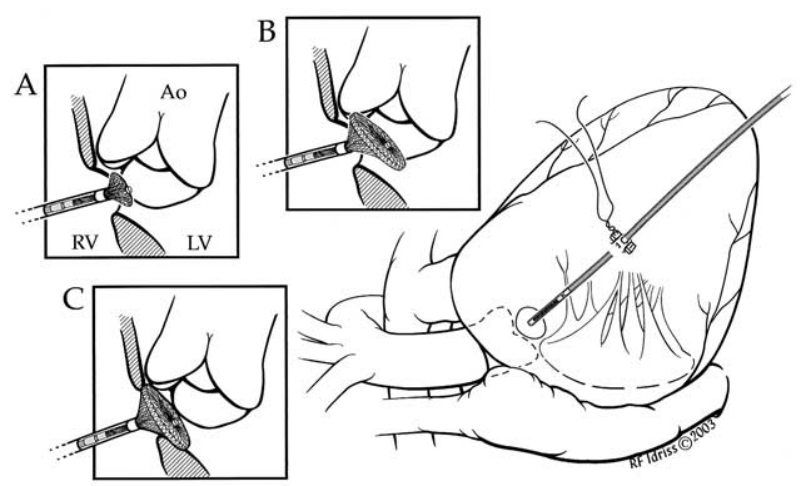

Figure 6. The delivery sheath is pulled until the tip is just under the aortic valve and the left disc is deployed (A). After deploying the left disc completely $(B)$, the delivery sheath is pulled back to approximate the left disc to the ventricular septum (C). Ao, Aorta; $R V$, right ventricle; $L V$, left ventricle.

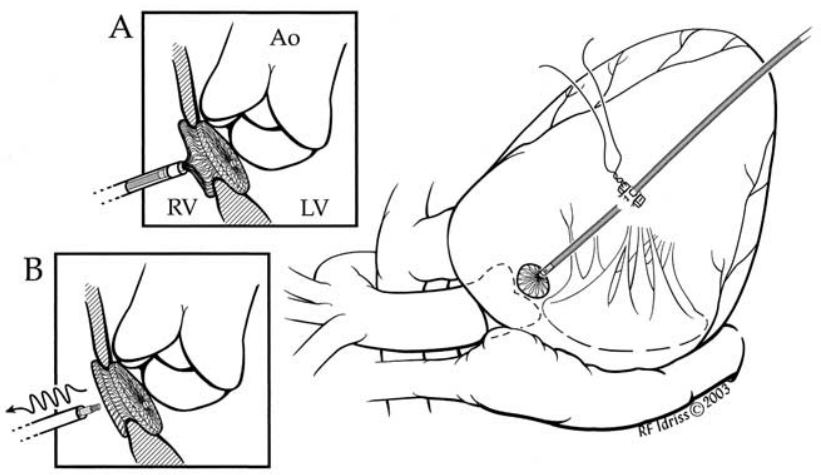

Figure 7. The right disc is deployed while keeping traction on the delivery cable (A). The device is released by rotating the delivery cable counterclockwise (B). Ao, Aorta; $R V$, right ventricle; $L V$, left ventricle.

wall was tied. Epicardial echocardiography was used to evaluate tricuspid or aortic regurgitation. The pericardium was partially closed, and a chest tube was placed in the mediastinum. The sternum was approximated with the help of sternal wires. The chest wall was closed in routine fashion. The animal was extubated on the operating room table. The chest tube was removed before the animal was transported back to the recovery room.

A total of 8 Yucatan pigs underwent closure of PMVSDs. Two pigs were killed immediately after the procedure. The remaining 6 pigs were kept alive for 6 to 7 months. The size of the PMVSD and the size of the sheaths and devices are outlined in Table 1.

Cardiac catheterization and angiography were performed at 3 and 6 months. The animals were killed after the 6-month angiogram. The heart was subjected to gross and microscopic examination.

\section{Results}

The procedure was successful in all animals. There was no incidence of device embolization or heart block. In one pig 
TABLE 1. Device and defect size

\begin{tabular}{lcc}
\hline PMVSD size & Sheath size & Device size \\
\hline $8 \mathrm{~mm}$ & $7 \mathrm{~F}$ & $10 \mathrm{~mm}$ \\
$4 \mathrm{~mm}$ and $8 \mathrm{~mm}$ & $7 \mathrm{~F}$ & $6 \mathrm{~mm}$ and $10 \mathrm{~mm}$ \\
$3 \mathrm{~mm}$ & $6 \mathrm{~F}$ & $4 \mathrm{~mm}$ \\
$5 \mathrm{~mm}$ & $6 \mathrm{~F}$ & $6 \mathrm{~mm}$ \\
$11 \mathrm{~mm}$ & $7 \mathrm{~F}$ & $12 \mathrm{~mm}$ \\
$6 \mathrm{~mm}$ & $6 \mathrm{~F}$ & $8 \mathrm{~mm}$ \\
$5 \mathrm{~mm}$ & $6 \mathrm{~F}$ & $6 \mathrm{~mm}$ \\
$7 \mathrm{~mm}$ & $7 \mathrm{~F}$ & $8 \mathrm{~mm}$ \\
\hline
\end{tabular}

PMVSD, Perimembranous ventricular septal defect.

the initial device had to be removed before it was released because of residual shunt. The device was replaced with a larger device. One pig had a PMVSD and an outlet (subarterial) VSD and hence required 2 devices. Angiograms obtained at 3 and 6 months after device placement showed no residual defect (Figure 8 ) or aortic insufficiency (Figure 9).

After the heart was explanted, saline was injected into the right ventricle to assess tricuspid valve leaflet coaptation. Complete coaptation was seen in all pigs. Gross examination of the heart from the left ventricular and right ventricular sides revealed complete coverage of the devices with the neoendocardium (Figures 10-12). The central area of the device was covered by a dense fibrocollagenous tissue. There were numerous inflammatory cells composed of foreign-body giant cells and histiocytes. The Dacron fibers were also surrounded by the foreign-body giant cells and histiocytes (Figure 13). There was extension of the scar tissue from the wire mesh to the surrounding cardiac tissue. The area adjacent to the aortic valve showed fibrosis and endothelial-like cells in the focal region. On the tricuspid valve side, valve adhesion to the edge of the device was seen in 3 pigs. The integrity of the tricuspid valve appeared preserved. Cartilaginous metaplasia of the myocardium toward the edge of the device was seen. There was no evidence of infection. All these findings were typical responses of the myocardium to the device.

\section{Discussion}

Intraoperative device closure of muscular VSDs has been described previously in the literature. ${ }^{9,10}$ However, all procedures were performed during $\mathrm{CPB}$. The results were not as good as expected initially, ${ }^{9}$ but slightly improved results were reported later. ${ }^{10}$ In the previous studies the main reason for disappointing results were use of a non-selfcentering device, a rigid delivery system, and no help from transesophageal or epicardial echocardiography during device placement because the heart was flaccid while the patient was under CPB.

The perventricular technique was introduced in 1997, and the first patient who underwent intraoperative device

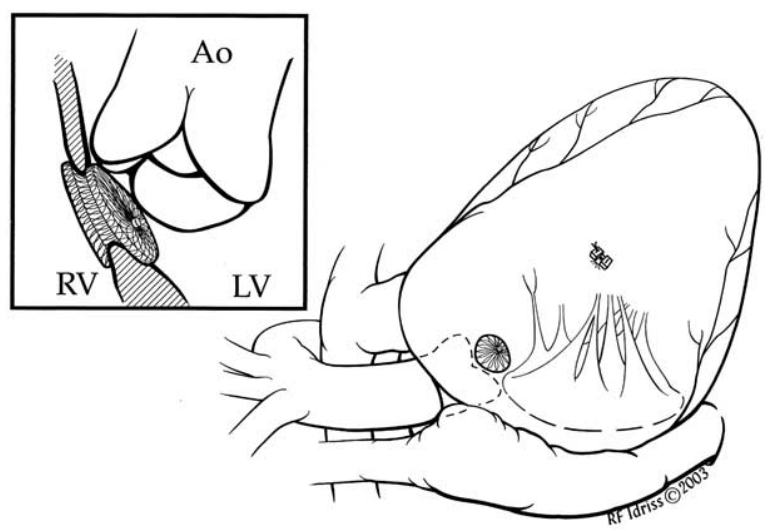

Figure 8. The delivery cable is pulled out of the right ventricle and the purse-string suture is tied. Ao, Aorta; RV, right ventricle; $L V$, left ventricle.

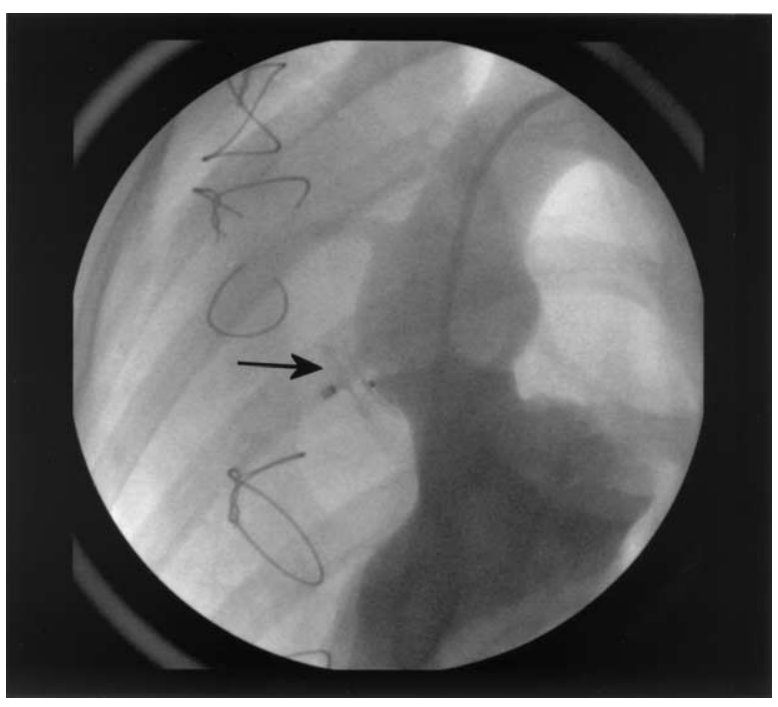

Figure 9. Left ventricular angiogram at 7 months' follow-up: no residual shunt is seen. The arrow points toward the device.

closure of a muscular VSD without CPB was reported by us in $1998 .{ }^{7}$ In 1999, we reported intraoperative device closure of a PMVSD through a left thoracotomy, but the results were not encouraging because a concentric device was used. ${ }^{8}$

Cumulatively, more than 19 patients have undergone closure of the muscular VSD with this technique, with good results. ${ }^{11,12}$ The success of this technique, when compared with that of previous attempts, lies in several factors. The first factor is that CPB is not used. The second factor is that the device placement and residual shunt can be evaluated by means of echocardiography because the heart is beating during the procedure. The third factor is that the delivery sheath is malleable and small in size when compared with that used in the previous experiments. The fourth factor is 


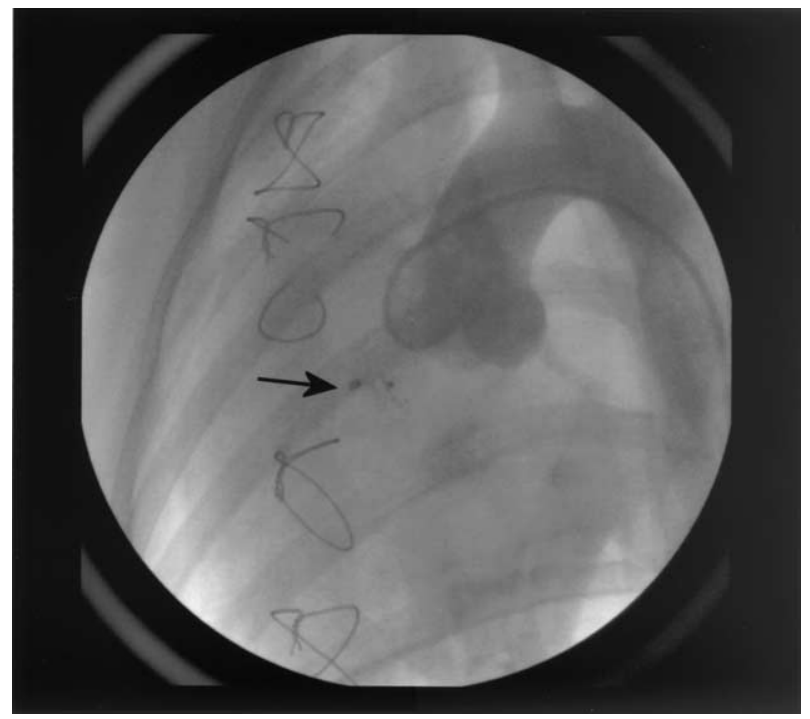

Figure 10. Ascending aortogram at 7 months' follow-up reveals no aortic insufficiency. The arrow points toward the device.

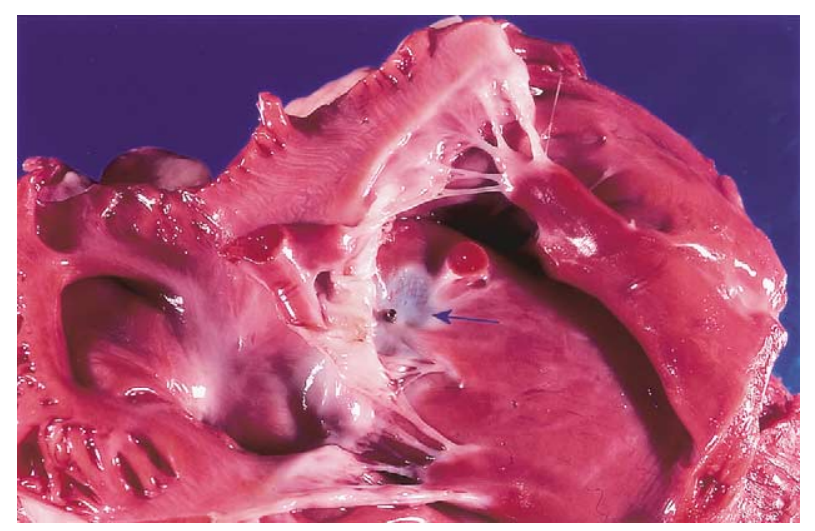

Figure 11. Amplatzer PMVSD occluder in situ 6 months after placement from the right ventricular side. The whole device is covered with glistening neoendocardium. The arrow points toward the device.

the design of the device. The Amplatzer device is a selfcentering, self-expanding, and fully retrievable device with a circular design. It is devoid of hooks or arms. The length of the connecting waist is small, which helps the device to approximate to the ventricular septum.

The last several years have seen significant advancement in minimally invasive techniques and increased use of devices. ${ }^{12-16}$ The deleterious effects of CPB in adult patients range from microbubbles, total body inflammatory responses, and postoperative cerebral dysfunction. ${ }^{17}$ The deleterious effects of $\mathrm{CPB}$ in pediatric patients without complex lesions remain unknown; however, transient and permanent neuropsychiatric injury has been reported in as many as $25 \%$ of patients. ${ }^{6}$ There is also risk of silent brain

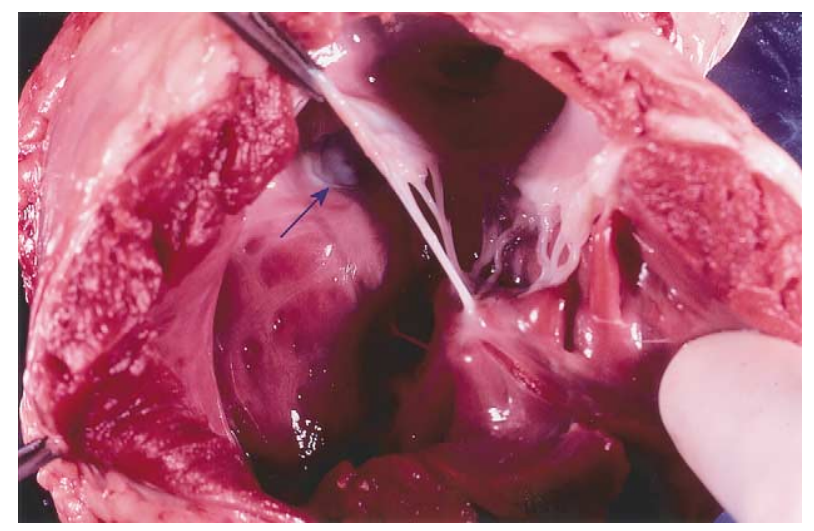

Figure 12. Device in situ from the left ventricular aspect. The device is completely covered by the neoendocardial layer. The arrow points toward the device.

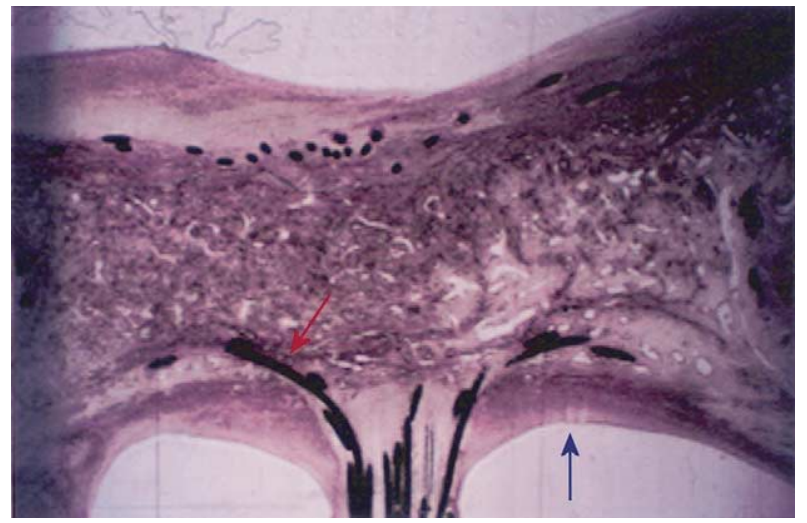

Figure 13. Higher magnification $(2.5 \times)$ of the middle portion of the implanted device. A layer of neoendocardium (red arrow) covers the device's wire mesh (green arrow). The Dacron fibers are surrounded by the granulation tissue, and vascularity is evident between the filaments of Dacron.

injury, even in patients who underwent isolated secundum atrial septal defect closure, as reported by Visconti and colleagues. ${ }^{18}$ Therefore avoiding CPB might decrease postoperative morbidity and mortality.

PMVSDs are among the most common congenital cardiac lesions, and hemodynamically symptomatic patients require closure earlier in infancy. These patients are failing to thrive because of congestive heart failure. Catheterization laboratory closure of the PMVSD in these patients is difficult and carries a high risk of complications because of large sheath size relative to patient size. The catheters are difficult to manipulate, which increases cardiac catheterization time, radiation, and risk of arrhythmia. The perventricular approach simplifies PMVSD closure. The potential complications of cardiac catheterization and fluoroscopy are avoided because the procedure is performed under echocardio- 
graphic guidance. The procedure is simplified because there are no acute turns of the catheter inside the heart. Because the procedure is performed on the beating heart, the procedure time is significantly reduced; the closure rate and the integrity of the aortic valve are evaluated before the device is released. Postoperatively, these patients are expected to recover faster than patients who have undergone closure during $\mathrm{CPB}$, as has been seen when patients underwent muscular VSD closure with this technique.

In summary, we believe that the perventricular technique is feasible and might open other avenues that can be used to close septal defects by using minimally invasive techniques, such as robotic surgery. Avoidance of $\mathrm{CPB}$ will decrease the immediate postoperative and long-term potential complications.

This study has some limitations. We did not evaluate tricuspid valve insufficiency by means of echocardiography at the time of death. The decision was based on poor transthoracic acoustics in pigs. The angiograms would have been unreliable because to assess tricuspid insufficiency, we had to cross the tricuspid valve with a catheter to perform an angiogram. The coaptation of the tricuspid valve leaflet was assuring after the heart was explanted.

Although there was no evidence of aortic valve insufficiency on the basis of angiography and no evidence of valve injury on the basis of gross or microscopic examination, there is potential for injuring the aortic valve with the delivery sheath or catheters. Similarly, we did not see any injury to the tricuspid valve, although the possibility exists. The wires and catheters used in the procedure are the usual catheters used during cardiac catheterizations in neonates and infants. Hence the chance of injuring the cardiac valves or other structures is low.

The risk of long-term problems with the aortic valve remains unknown. Long-term follow-up will be needed in human subjects. We do not believe it to be a problem because the device does not encroach on the aortic valve.

\section{References}

1. Mitchell SC, Korones SB, Berendes HW. Congenital heart disease I 56,109 births. Circulation. 1971;43:323-32.

2. Kidd L, Driscoll DJ, Gersony WM, et al. Second natural history study of congenital heart defects: results of treatment of patients with ventricular septal defects. Circulation. 1993;87(suppl I):138-51.

3. Rudolph AM. Ventricular septal defect. In: Rudolph AM, editor. Congenital diseases of the heart: clinical-physiological considerations. 2nd ed. Armonk, NY: Futura; 2000. p. 197-244.

4. Backers CL, Winters RC, Zales VR, et al. The restrictive ventricular septal defect: how small is too small to close? Ann Thorac Surg. 1993;56:10-4.

5. Rose EA. Off-Pump coronary artery bypass surgery. $N$ Engl J Med. 2003;348:379-80

6. Kern FH, Hickey PR. The effects of cardiopulmonary bypass on the brain. In: Jonas RA, editor. Cardiopulmonary bypass in neonates, infants and young children. 1st ed. Boston: Blackwell Science; 1994. p. $263-78$.

7. Amin Z, Berry JM, Rocchini AL, Bass JL. Intraoperative closure of muscular ventricular septal defects in a canine model and application of the technique in a baby. J Thorac Cardiovasc Surg. 1998;115: 1374-6.

8. Amin Z, Gu X, Berry JM, Titus JL, Gidding SL, Rocchini AL. Perventricular closure of ventricular septal defects without cardiopulmonary bypass. Ann Thorac Surg. 1999;68:149-54.

9. Fishberger SB, Bridges ND, Keane JF, et al. Intraoperatiove device closure of ventricular septal defects. Circulation. 1993;88(suppl): 205-9.

10. Okubo M, Benson LN, Nykanen D, et al. Outcomes of intraoperative device closure of muscular ventricular septal defects. Ann Thorac Surg. 2001;72:416-23.

11. Amin Z, Berry JM, Danford DA, Foker JE, Duncan KF, Bass JL. Intraoperative closure of muscular ventricular septal defects without cardiopulmonary bypass: preliminary results of the perventricular approach. Circulation. 2001;104(suppl 17):II-710.

12. Bacha E, Cao Q, Starr JP, Waight D, Ebeid M, Hijazi ZM. Perventricular device closure of muscular ventricular septal defects on the beating heart: technique and results. J Thorac Cardiovasc Surg. 2003. In press.

13. Lin PJ, Chang C, Chu J. Minimally invasive cardiac surgical techniques in the closure of ventricular septal defects: an alternative approach. Ann Thorac Surg. 1998;65:165-70.

14. Hijazi ZM, Hakim F, Haweleh A, et al. Catheter Closure of perimembranous ventricular septal defects using the new Amplatzer membranous VSD occluder. Catheter Cardiovasc Interv. 2002;56:508-15.

15. Suematsu Y, Takamoto S, Kaneko Y, et al. Beating atrial septal defect closure monitored by realtime three dimensional echocardiography without cardiopulmonary bypass. Circulation. 2003;107:785-90.

16. Kalra GS, Verma PK, Dhall A, Singh S, Arora R. Transcatheter device closure of ventricular septal defects: immediate results and intermediate term follow-up. Am Heart J. 1999;138:339-44.

17. Jaegere PP, Suyker WJ. Off-pump coronary artery bypass surgery. Heart. 2002;88:313-8.

18. Visconti KJ, Bichell DP, Jonas RA, Newburger JW, Bellinger DC. Developmental outcome after surgical versus interventional closure of secundum atrial septal defect in children. Circulation. 1999;100(suppl 19):III 145-50.

\section{Discussion}

Dr Emile A. Bacha (Chicago, Ill). Amin and colleagues performed PMVSD closure in 8 large animals, which were kept alive for 6 months. They were successful in all cases and have presented solid angiographic and histologic evidence that this technique is feasible and safe in the medium term. Dr Amin, I congratulate you for pioneering the field of intraoperative device closure. I also commend you on presenting your data to a surgical audience as opposed to an interventional meeting. After all, surgeons have been involved with VSD closure for more than 30 years.

On the basis of your data and the preliminary US Food and Drug Administration trial data, it appears that device closure of a membranous VSD is safe at medium term. However, the aortic valve is at risk for either immediate injury or long-term dysfunction. Long-term results are awaited in that respect. I disagree with your description of CPB as being deleterious. Most studies showing the deleterious effects of CPB were done either in adults with atherosclerosis or in neonates with complex malformations. Having said that, I believe that perventricular device closure is here to stay and that surgeons should firmly embrace and study this new technology. As you know, we have now performed perventricular muscular VSD closure in 6 patients, and all of those procedures were successful. I have 3 questions for you.

What is your opinion of the long-term effect of the device on aortic valve function given the proximity of the device? In neonates and infants, do you think that the disks protruding in the 
outflow tract might result in outflow obstruction? I noticed that the lowest weight of the pigs was $16 \mathrm{~kg}$. Typically, the patients we operate on would be much smaller than that.

The third question is, because of the need for precise positioning of the device, with the flat side toward the aortic valve, and thus the need to rotate the entire delivery assembly, do you believe that this technique would be easier to apply through a perventricular approach in the operating room, as you have shown, as opposed to a percutaneous approach from the groin? Thank you very much.

Dr Amin. Thank you, Dr Bacha. As to your first question about the long-term follow-up, as you mentioned, the pigs weighed anywhere from 17 to about $53 \mathrm{~kg}$. Excluding one pig that weighed $53 \mathrm{~kg}$, all remaining pigs weighed less than $30 \mathrm{~kg}$ and were less than 3 months old. Therefore they really were small in size and young. During the follow-up period of 6 months, there was tremendous weight gain. One of the pigs that weighed only $16 \mathrm{~kg}$ at the time the device was placed weighed more than $100 \mathrm{~kg}$ at the time of death. I think that is a significantly long follow-up period in pig years. Therefore they really matured into adulthood, if you will.

But in human terms, I am not sure what the long-term follow-up will hold. If you do look at the devices that were placed in 1989 in muscular VSDs-and sometimes those devices were also placed in the perimembranous area-although their immediate and acute results were not very good, long-term data are lacking. I totally agree with you that we will find out what the long-term results are in about 5 to 10 years. China has performed almost 300 perimembranous VSD closures with this device over the last $2 \frac{1}{2}$ years. During follow-up, they had 6 patients who had trace to mild aortic insufficiency. Unfortunately, I cannot tell you exactly what their criteria for trace or mild insufficiency are unless and until I review the echocardiograms.

In regard to your second question about CPB, I simply believe that no matter how simple or complex the patient's condition is, no $\mathrm{CPB}$ is preferable.

As to your last question about positioning the device, how the flat edge has to face or should face the aortic valve, I agree with you that it is easier to do in the operating room because we can rotate the sheath very easily clockwise or anticlockwise as opposed to when we are performing the procedure in the cardiac catheterization laboratory because we lose the torque on the sheath. In the operating room it is relatively easier.

Dr Ross M. Ungerleider (Portland, Ore). Zahid, you are to be complimented on something very innovative, not just the use of a device but also the concept of truly collaborative work. The Institute of Medicine has been telling us for years that to improve patient safety, we need to become more team oriented and multidisciplinary in our approach to disease, and for you to get out of the silo of the catheterization laboratory and to begin to collaborate with surgeons in the operating room might open up the doors for several innovations for the treatment of congenital heart disease in babies as we combine our efforts. We have done that with intraoperative stenting and now with these devices. I have 2 questions for you.

Tell us a little bit about the kind of anatomy that these Yucatan pigs have with their perimembranous VSDs. It is my experience that human infants can sometimes have very complex relationships between the tricuspid valve chordal mechanisms and the VSD that might make it somewhat difficult to position the device without creating significant tricuspid insufficiency. Is the same kind of chordal relationship complexity true of the Yucatan pigs?

The second question is, have you considered using this device in an open fashion, although it does require the infants being placed on bypass, to close multiple muscular VSDs, or even to position it precisely in a perimembranous location, which might be easier than sewing a patch in place?

Again, I congratulate you on the true innovation, which is the collaboration with your surgical colleagues, because together I suspect we could innovate terrific things in the future.

Dr Amin. Thank you, Dr Ungerleider. The anatomy of the perimembranous VSDs in pigs is actually very similar to that seen in human subjects. The complexity of the chordal attachment of the septal leaflet of the tricuspid valve in pigs is very much similar to the chordal attachment of the leaflets in human subjects. Our pathology data revealed that some chordae were trapped underneath the right disc, but the tricuspid insufficiency was never more than mild, which I believe is acceptable and similar to the surgical results. The VSD is just under the anteroseptal commissure of the tricuspid valve, just as it is in human subjects.

The only difference that pops in my mind at the current time is that the pigs have a higher propensity for aneurysm formation and hence possibly a higher chance of spontaneous closure. The pig hearts have been examined by a few pathologists in the past, and they found that the pig hearts were similar to human hearts.

In regard to your second question, although we have not looked at closing the defects in an open fashion, I believe it will be very much feasible, especially in patients with muscular VSDs. The only disadvantage I can foresee is that we will not be able to determine whether the patient has a residual defect because the heart will be flaccid.

Dr Marian Zembala (Zabrze, Poland). I would compliment your work for 2 reasons on the basis of our experience, closure of 12 patients with post-VSD by nonoperating field by interventional cardiologists. We lost 12 patients; all of them were at higher risk. That is why we did not decide on surgery. One we lost in the sixth postoperative week because of multiorgan failure and septicemia caused by long-term radiation instead of short-term radiation. When you close an atrial septal defect, the VSD is much longer, and I think this teamwork helped to avoid this long radiation.

Anyway, I think it is a good approach, even for more difficult patients, such as those who have postinfarction VSD.

Dr Amin. Thank you.

Dr Carlos J. Troconis (Caracas, Venezuela). Congratulations for your innovative technique. I have 2 questions. The first one is, we have observed in those patients with a perimembranous VSD that some of them do not have an infundibular ventricular infold rim. And I noticed in your slides that these pigs have a rim of muscle (septum) between the tricuspid valve and the aortic valve. Therefore would the placement of your device sometimes be difficult if there is a lack of such morphology?

The second question is, does the 3-dimensional echocardiography enhance your technique?

Dr Amin. Thank you. I believe that you are asking me about the rim of tissue that we find under the aortic valve. If there is a complete absence of the rim, it is conceivable that the device might impinge on the aortic valve and cause insufficiency or the patient 
might have a residual defect. The perimembranous VSD device design has a flat edge, with the rim measuring only $0.5 \mathrm{~mm}$ more than the disk. In addition, in phase I trials in the United States, all patients with any evidence of aortic insufficiency will be excluded, and the patient's weight will have to be more than $8 \mathrm{~kg}$. Therefore hopefully we can avoid this potential complication. I believe that this device is not going to be suitable for all the patients with perimembranous VSDs.

Concerning your second question about the 3-dimensional echocardiogram, I completely agree with you that it should enhance the visibility and precise placement, and we are working with one company at the current time. 